\title{
Research on Mathematical Model of Cost Budget in the Early Stage of Assembly Construction Project Based on Improved Neural Network Algorithm
}

\author{
Xin Lin $\mathbb{D i D}^{1}$ and Yinan $\operatorname{Lu} \mathbb{D}^{2}$ \\ ${ }^{1}$ School of Urban Construction Engineering, Chongqing Radio \& TV University, Chongqing, China \\ ${ }^{2}$ School of Information Engineering, Nanchang University, Nanchang, China \\ Correspondence should be addressed to Xin Lin; lxcqrtvu_edu@126.com
}

Received 2 May 2020; Accepted 25 June 2020; Published 15 July 2020

Academic Editor: Jia-Bao Liu

Copyright (c) 2020 Xin Lin and Yinan Lu. This is an open access article distributed under the Creative Commons Attribution License, which permits unrestricted use, distribution, and reproduction in any medium, provided the original work is properly cited.

In view of the poor performance of the original mathematical model of assembly construction project precost budget, a mathematical model of assembly construction project precost budget based on improved neural network algorithm is proposed. This paper investigates the cost content of assembly construction project and analyzes its early cost. It finds that the early cost of assembly construction project includes component production cost, transportation component cost, and installation component cost. Based on the improved neural network algorithm to build an improved neural network model, the improved neural network model to mine the cost data in the early stage of assembly construction project is used. In this paper, the earned value variable is introduced to transform the project duration and project cost in the early stage of the prefabricated construction project into quantifiable cost data, and the earned value analysis method is used to estimate the implementation cost of the prefabricated construction project. According to the result of cost estimation, the mathematical model of precost budget of prefabricated construction project is built based on the project parameters. In order to prove that the cost budget performance of the mathematical model based on the improved neural network algorithm in the early stage of assembly construction project is better, the original mathematical model is compared with the mathematical model, the experimental results show that the cost budget performance of the model is better than the original model, and the cost budget performance is improved.

\section{Introduction}

In traditional construction projects, the pouring of concrete mainly adopts manual scaffolding, formwork supporting, and binding of steel bars at site. However, such kind of castin-place can cause a variety of problems, including making construction site in a mess, generating lots of construction waste, and polluting the surrounding environment [1]. Meanwhile, with the progress of population aging and the increase of labor costs in China, this extensive construction model is no longer suitable for the green, energy-saving, and environmentally friendly concepts. Under this circumstance, the prefabricated construction project emerged at the right moment and eased this dilemma. As a new building construction technology, prefabricated construction project means to process and produce the prefabricated components in factory, move them to the construction site after maintenance, and then assemble the building components accordingly through machinery equipment to achieve the building functional requirements [2]. Compared with the cast-in-place construction method, the prefabricated construction project can save about $20 \%$ of materials and $80 \%$ of water resources in manufacturing and processing building components. At the same time, in prefabricated construction project, protective nets and scaffolding are not used during construction, which reduced construction waste and lowered the pollution and harm to the environment [3].

Under the trend of urbanization, people have put forward higher requirements for environmental protection and energy-saving performance of buildings. Therefore, 
prefabricated buildings are getting popular, have achieved rapid development in China, and promoted the improvement of the installation quality and component precision of prefabricated components [4]. However, based on the current construction market, the overall production scale of prefabricated buildings is restricted so that it is unable to reduce the construction cost budget through expanding the scale, which limited the development of prefabricated buildings in China and affected the industrialization process of construction field. At its initial stage of development, prefabricated buildings in China are still facing many shortcomings in technology, experience, and cost control [5]. In order to accelerate the development of prefabricated buildings, an innovative research on the mathematical model of cost budget in early stage of prefabricated construction is carried out. On this basis, a mathematical model of cost budget in the early stage of prefabricated construction project based on improved neural network algorithm is proposed [6].

\section{Design of Mathematical Model of Cost Budget in the Early Stage of Prefabricated Construction Project Based on Improved Neural Network Algorithm}

2.1. Analysis of Cost in the Early Stage of Prefabricated Construction Project. As found in the cost analysis in early stage of the prefabricated construction project, the preliminary cost of prefabricated construction project includes component production cost, component transportation cost, and component installation cost. Among them, statistics found that component production cost contains labor cost, material cost, mold cost, amortization expense, cost of setting the embedded parts and pipelines, management and storage cost, and water and electricity charges. The specific contents are shown in Table 1 [7].

Component transportation cost covers the cost of transporting components from the factory to the construction site, which is directly related to the size and weight of the components, as well as the distance between the factory and the construction site [8].

Component installation costs involves the cost of vertical component transportation, labor cost of component installation, machinery cost of component installation, material cost of component installation, cast-in-place cost, and amortization cost, as shown in Table 2 [9].

2.2. Data Mining of Cost in the Early Stage of Prefabricated Construction Project. As shown in the analysis of cost budget in early stage of prefabricated construction project, an improved neural network model is built based on the improved neural network algorithm so as to conduct data mining on the cost budget in early stage of prefabricated construction project [10]. The specific steps are as follows:

(1) First, the improved neural network is initialized: $(X, Y)$ is adopted to represent the input and output sequence of the improved neural network. Based on this sequence, the specific number of nodes corresponding to the output layer, hidden layer, and input layer of the improved neural network is clarified, which is $m, l$, and $n$ nodes, respectively. Next, the threshold and the connection weight are initialized. The neuron connection weight between the hidden layer and the input layer is set to $\omega_{i j}$; the neuron connection weight between the output layer and the hidden layer is set to $\omega_{j k}$; the thresholds of the output layer and hidden layer is $b$ and $a$, respectively. Finally, the learning rate of the improved neural network is set to $\eta$, and the excitation neuron function is set to $f(x)$ [11].

(2) The specific output of the hidden layer is computed: the specific output of the hidden layer is obtained based on the specific input variable $X$ of the improved neural network, the threshold value $a$ of the hidden layer, and the neuron connection weight $\omega_{i j}$ between the hidden layer and the input layer. The details are as follows:

$$
\left\{H_{j}=f\left(\sum_{i=1}^{n} \omega_{i j} x_{i}-a_{j}\right), \quad j=1,2,3, \ldots, l\right.
$$

In formula $1, H_{j}$ represents the specific output of the hidden layer, $x_{i}$ represents the $i$ th input value, $a_{j}$ represents the threshold of the $j$ th hidden layer, and $l$ represents the specific number of nodes of the hidden layer [12].

(3) The specific output of the input layer is computed: the specific output of the input layer is obtained according to the specific output $H_{j}$ of the hidden layer, the threshold value $b$ of the output layer, and the neuron connection weight $\omega_{j k}$ between the output layer and the hidden layer:

$$
\left\{O_{k}=\sum_{i=1}^{l} H_{j} \omega_{j k}-b_{k}, \quad k=1,2,3, \ldots, m\right.
$$

In forrmula $2, O_{k}$ represents the specific output of the input layer and $b_{k}$ represents the threshold of the $k$ th output layer [13].

(4) Error calculation: the specific error of the improved neural network is predicted based on the specific output of the input layer and the specific expected output $Y$ of the improved neural network.

(5) The neuron connection weight $\omega_{i j}$ between the hidden layer and the input layer, and the neuron connection weight $\omega_{j k}$ between the output layer and the hidden layer are updated according to the specific predicted error of the improved neural network.

(6) Threshold updating: the thresholds $b$ and $a$ of the output layer and hidden layer are updated according to the specific predicted error of the improved neural network.

(7) The construction of improved neural network model is realized and the data mining on the cost in early 
TABLE 1: Component production cost.

\begin{tabular}{|c|c|c|}
\hline No. & Name of cost & Content of cost \\
\hline 1 & Labor cost of component & igher salaries shall be paid to profes \\
\hline 2 & Material cost of component $\mathrm{p}$ & materials as required by the traditional construct \\
\hline 3 & Mold cost of component prod & $\begin{array}{c}\text { Cost of table molding, binding steel bar mold, concrete pouring mold, maintenance mold, } \\
\text { and finished component mold }\end{array}$ \\
\hline 4 & & ad specific quantities of molds \\
\hline 5 & $\begin{array}{l}\text { Cost of setting the embedded parts and } \\
\text { pipelines }\end{array}$ & $\begin{array}{r}\text { Costs incurred in arranging the embedded parts and pip } \\
\text { components, mainly the pipeline } \mathrm{cc}\end{array}$ \\
\hline & Manageme & gement an \\
\hline & Water and electricity charges & Electricity and water charges incurred by factory component production \\
\hline
\end{tabular}

TABLE 2: Component installation cost.

\begin{tabular}{|c|c|c|}
\hline No. & Name of cost & Content of cost \\
\hline 1 & $\begin{array}{l}\text { Cost of vertical component } \\
\text { transportation }\end{array}$ & Cost of vertically hoisting components \\
\hline 2 & $\begin{array}{l}\text { Labor cost of component } \\
\text { installation }\end{array}$ & $\begin{array}{c}\text { Higher labor salaries shall be paid because the vertical hoisting of components requires higher } \\
\text { professionalism and proficiency. }\end{array}$ \\
\hline 3 & $\begin{array}{l}\text { Machinery cost of component } \\
\text { installation }\end{array}$ & The cost generated by using machinery equipment during component installation \\
\hline 4 & $\begin{array}{l}\text { Material cost of component } \\
\text { installation }\end{array}$ & Costs incurred by filling materials and connectors \\
\hline 5 & Cast-in-place cost & Cast-in-place cost for assembly \\
\hline 6 & Amortization cost & Amortization cost of tools \\
\hline
\end{tabular}

stage of prefabricated construction project is performed on this basis [14].

\subsection{Cost Budget in Early Stage of Prefabricated Construction} Project. Based on the data mining of cost in early stage of prefabricated construction project, a variable called earned value is introduced to convert the project duration and project cost in early stage of prefabricated construction into quantifiable cost data. Meanwhile, the cost in early stage of prefabricated construction project is estimated through the earned value analysis so as to carry out the cost budget of prefabricated construction project [15]. The calculation formula of earned value is as follows:

$$
E V=A \times B .
$$

In formula 3, $E V$ represents earned value, $A$ represents the project actual workload and $B$ represents the cost budget of the completed project.

For the analysis by using the earned value, the difference variables of two analyzes must be obtained at first, including schedule deviation and cost deviation. Their calculation formulas are separately as follows:

$$
S V=B-B S W S \text {. }
$$

In formula $4, S V$ represents the schedule deviation and $B S W S$ represents the cost budget of planned project volume.

$$
C V=B-A C W P \text {. }
$$

In formula 5, $C V$ represents cost deviation and $A C W P$ represents the specific cost of the completed project volume [16].
Along with two variable indexes, including performance progress index and performance cost index, the calculation formulas are as follows:

$$
S P I=\frac{B}{B C W S} .
$$

In formula $6, S P I$ represents the performance progress index:

$$
C P I=\frac{B}{A C W P}
$$

In formula $7, C P I$ represents the performance cost index.

The data of the cost budget of completed project volume, the specific cost of completed project volume, and the cost budget of planned project volume are added separately [17] in analysis so that 3 corresponding cumulative series are obtained. By inputting data of cost budget of completed project volume, the specific cost of completed project volume and the cost budget of planned project volume into a two-dimensional coordinate axis of time and cost, and 3 analysis curves are obtained and applied to analyze the period and cost in early stage of prefabricated construction project. Among them, when the cost deviation is greater than 0 , it indicates that the early stage of prefabricated construction project is in a cost-saving state; when the cost deviation is less than 0 , it indicates that the early stage of prefabricated construction project is in the over-cost state; when the progress deviation is greater than 0 , it indicates that the early stage of prefabricated construction project is in a state of advanced progress; when the progress deviation is less than 0 , it indicates that the early stage of prefabricated construction project is in a state of delayed progress. The cost 
of prefabricated buildings can be estimated by inputting the construction period and cost analysis results of early stage of the prefabricated construction project as well as the actual status of the early stage of project into the project management software.

2.4. Mathematical Model of Cost Budget in Early Stage of Prefabricated Construction Project. According to the estimated cost in the early stage of prefabricated construction project, the mathematical model of cost budget in early stage of prefabricated construction project is constructed based on project parameters. The items of material budget in early stage of prefabricated construction project are shown in Table 3.

The project parameters are described according to the type of project, in which the parameter of production progress in the early stage of prefabricated construction project is set to $r_{g}$, the parameter of production calculation period is set to $T$, the parameter of periodic component production batch is set to $N$, labor demand cost is set to $L(P)$, machinery demand cost is set to $L(c)$, other expenses such as management fee are set to $K$, demand machinery value is set to $F_{L}$, site cost is set to $A_{C}$, equipment rental cost is set to $F(c)$, the upper limit of transportation cost is set to $P(c)$, and the assembly cost is set to $A_{\text {sum }}$.

The production process in early stage of prefabricated construction project can be summarized as follows: the first if component production, followed by component assembly and transportation. In this way, the cost in early stage of prefabricated construction project includes construction production cost, component assembly, and transportation fee [19]. Therefore, by setting parameters of production progress in early stage of prefabricated construction project as independent variables and the minimum budget cost as the model objective function, then the mathematical model of cost budge in the early stage of prefabricated construction projects is established as follows [20]:

$$
\left\{\begin{array}{l}
r_{g}=\frac{T}{N}, \\
\operatorname{MinCost}=A(c) \int_{0}^{T} L(p) \mathrm{d} t+L(c) \int_{0}^{T} A \mathrm{~d} t+F(L) \int_{0}^{T} F(c) \mathrm{d} t+K \cdot P(c) \cdot A_{\text {sum }} .
\end{array}\right.
$$

In formula 8 , MinCost represents the minimum cost budget in the early stage.

\section{Experimental Research and Result Analysis}

3.1. Experiment Design. The experiment of cost budget in early stage of prefabricated construction project is carried out by using the mathematical model of cost budget in early stage of prefabricated construction project designed based on improved neural network algorithm. With a total area of 920 square meters, the prefabricated construction project in this experiment contains 14 floors in prefabricated structures of assembled shear wall. The prefabricated component nodes are manufactured by secondary cast-in-place. The outer wall of the building is made of prefabricated thermal insulation Sandwich panel; the floor is made of concrete prestressed composite slab; the load-bearing wall is made of shear prefabricated wall panel; the staircase is prefabricated; the inner partition wall is made of lightweight wall panel. The prefabricated parts involved in this prefabricated construction project are listed as follows: prefabricated parts for stair, prefabricated parts for laminated panel, prefabricated parts for partition wall, shear wall, etc. Considering that it is a prefabricated construction project, all the prefabricated parts are produced at the prefabricated production base and then transported to the construction site after maintenance. Meanwhile, the transportation and production of prefabricated parts for different places and floors are arranged separately according to the specific project progress.
The specific building parameters of this prefabricated building project are shown in Table 6 .

In this prefabricated construction project, all the floors are standard, and the early stage is set to a six-day construction period per floor. According to the building structure and engineering quantity, the construction sequence is arranged reasonably and the whole project is divided into three phases. The specific arrangements for the construction of each floor are as follows: hoisting 60 pieces of wall in the first construction phase, hoisting 60 pieces of wall in the second construction phase, grouting sleeve in the first construction phase, grouting sleeve in the second construction phase, hoisting 30 pieces of wall in the third construction phase, grouting sleeves in the third construction phase, binging steel bars with postcasting belts, reinforcing formwork with postcasting belts, erecting supportive frames, hoisting composite beams, hoisting stairs, hoisting of 60 pieces of composite slabs, hoisting 57 pieces of composite slabs, preburying hydropower and other pipelines, binding the upper stair reinforcement, supporting formwork joints, and pouring concrete. The cost budget in early stage of this prefabricated building construction is estimated through the mathematical model. In order to ensure the effectiveness and contrast of this experiment, the original mathematical model of cost budget in the early stage of prefabricated construction project is compared to the mathematical model of cost budget in the early stage of prefabricated construction project designed based on the improved neural network algorithm in this paper. Among 
TABLE 3: Items of material budget in early stage of prefabricated construction project.

\begin{tabular}{lrr}
\hline No. & Items of material budget & Unit \\
\hline 1 & Prefabricated PC wall components & Cubic meter \\
2 & Prefabricated PC floor (laminated) components & Cubic meter \\
3 & Prefabricated PC stair components & Cubic meter \\
4 & Prefabricated PC balcony components & Cubic meter \\
5 & Prefabricated PC air conditioning panel components & Cubic meter \\
6 & Prefabricated PC beam components & Cubic meter \\
7 & Rebar B300HR(D $<25)$ & Ton \\
8 & Screw-thread steel B225HR(D $<12)$ & Ton \\
9 & Concrete C30 (premixed) & Cubic meter \\
10 & Concrete C35 (premixed) & Cubic meter \\
11 & Fine stone concrete C20 (premixed) & Cubic meter \\
12 & Aerated light sand autoclaved block concrete & Cubic meter \\
13 & Specialized component grouting & Ton \\
14 & Remaining self-purchased materials (estimated value) & - \\
\hline
\end{tabular}

The items of labor cost budget in early stage of prefabricated construction project are shown in Table 4 [18].

TABLE 4: Items of labor cost budget in early stage of prefabricated construction project.

\begin{tabular}{lrc}
\hline No. & Items of labor cost & Unit \\
\hline 1 & Manual cleaning of foundation pit & Cubic meter \\
2 & Tanual lashing of cast-in-place and steel bar making & Cubic meter \\
3 & Manual assembly and wooden template making & Cubic meter \\
4 & Manual maintenance of cast-in-place and concrete pouring & Cubic meter \\
5 & Manual installation of prefabricated PC components & Cubic meter \\
6 & Tower crane driver, surveyor, and bell man & Cubic meter \\
7 & Manual masonry & Cubic meter \\
8 & Manual water resistance & Cubic meter \\
9 & Manual fitment & \\
\hline
\end{tabular}

The items of machinery budget in early stage of prefabricated construction project are shown in Table 5 .

TABLE 5: Items of machinery budget in early stage of prefabricated construction project.

\begin{tabular}{lccc}
\hline No. & Name & Unit & Type \\
\hline 1 & (Tower) crane & Set & ST50/20 \\
2 & Car crane & Set & $26 \mathrm{~T}$ \\
3 & Material hoist & Set & SES160 \\
\hline
\end{tabular}

TABLE 6: Specific building parameters of this prefabricated building project.

\begin{tabular}{lcc}
\hline No. & Name of building parameters & Specific parameters \\
\hline 1 & Height & $40 \mathrm{~m}$ \\
2 & Floors & 14 \\
3 & Structure type & Prefabricated structure of assembled shear wall \\
4 & Specific floor height & $3.6 \mathrm{M}$ at $1^{\text {st }}$ floor \\
5 & Covered area & $2.8 \mathrm{M}$ from $2^{\text {nd }}$ to $14^{\text {th }}$ floor \\
6 & Seismic grade & $920 \mathrm{~m}^{2}$ \\
7 & Seismic intensity & 4.0 magnitude \\
8 & Specific flame resistance & Scale 6 \\
9 & Specific waterproof rating & Level 2 \\
& & Level 2 \\
11 & Specific type of prefabricated part & Shear wall \\
& & Partition wall \\
12 & Building nature & Composite slab \\
13 & Plan view size & Platforms, ladder beams, stairs \\
15 & Production materials such as windows and doors & $15 \times 40$ \\
\hline
\end{tabular}

The specific contracting situation of this prefabricated construction project is shown in Table 7. 
TABLE 7: Specific contracting situation of this prefabricated construction project.

\begin{tabular}{lcc}
\hline No. & Items & Specific situation \\
\hline 1 & Specific project name & Project of Fuligang building \#2 \\
2 & Construction company & Haoqiang Real Estate co., ltd \\
3 & Design contractor & Yicai Architectural Design co., ltd \\
4 & Supervision company & Keli Supervision Construction co., ltd \\
5 & Construction organization & Risheng Engineering Cconstruction co., ltd \\
6 & Quality supervision organization & Yihe Engineering Quality Supervision co., ltd \\
7 & Total project cost & RMB 12.6 million \\
8 & Contracted form & Contract for labor and material \\
9 & Contract scope & Decoration, main body, foundation \\
10 & Planned schedule & One year \\
11 & Overall quality goal & Good in quality \\
\hline
\end{tabular}

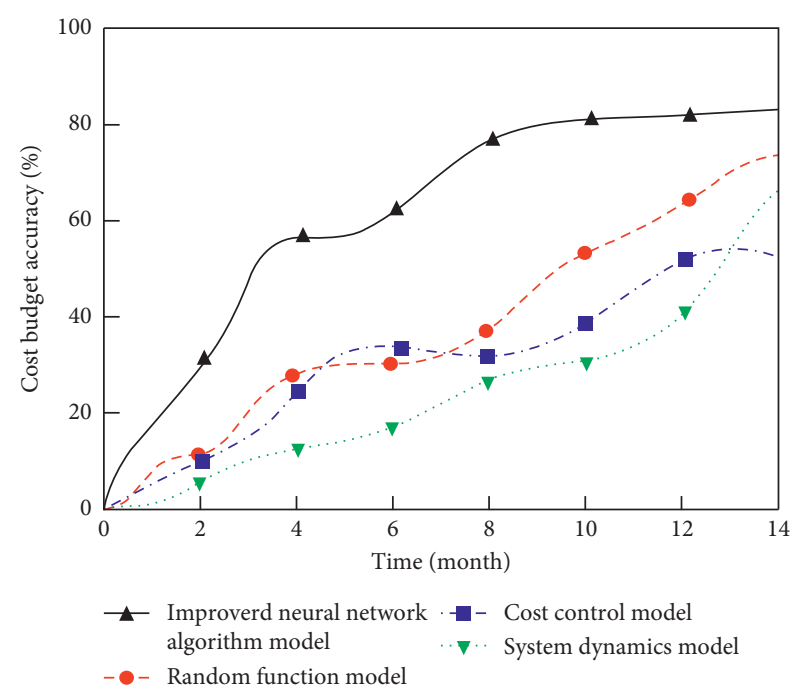

Figure 1: Result of comparative experiment on cost budget performance.

them, the original mathematical model of cost budget in early stage of prefabricated construction project includes the mathematical model of cost budget in early stage of prefabricated construction project based on cost control, random function, and system dynamics. As learned from comparing the performance of different mathematical models of cost budget in early stage of prefabricated construction project, that is, from analyzing the cost budget accuracy of the experimental model, the higher the cost budget accuracy, the more reasonable the cost budget result of the prefabricated construction project and the better cost budget performance [21].

3.2. Analysis Results. The result of comparative experiment on cost budget performance between the original mathematical model of cost budget in early stage of prefabricated construction project and the mathematical model of cost budget in early stage of prefabricated construction project designed based on the improved neural network algorithm is shown in Figure 1.

According to the result of comparative experiment on cost budget performance between two different mathematical models, the mathematical model of cost budget in early stage of prefabricated construction project designed based on the improved neural network algorithm is better in cost budget accuracy. That means the cost budget performance of the mathematical model of cost budget in early stage of prefabricated construction project based on the improved neural network algorithm is superior to that of the original mathematical model of cost budget in early stage of prefabricated construction project.

\section{Conclusions}

The cost budget performance of the mathematical model of cost budget in the early stage of prefabricated construction project based on the improved neural network algorithm can realize the improvement of cost budget performance in the early stage of prefabricated construction project, which is of great reference significance to accurate cost budget of the overall prefabricated construction project.

\section{Data Availability}

Simulation data and our model and related hyperparameters used are provided within the article.

\section{Conflicts of Interest}

The authors declare that they have no conflicts of interest.

\section{Acknowledgments}

This work was supported by the Chongqing Municipal Education Commission Science and Technology Research Project (KJQN201904003) and research project of Chongqing Technology and Business Institute (ZD2016-04).

\section{References}

[1] G. E. Gurcanli, S. Bilir, and M. Sevim, "Activity based risk assessment and safety cost estimation for residential building construction projects," Safety Science, vol. 80, pp. 1-12, 2015.

[2] Y. T. Chae, R. Horesh, Y. Hwang, and Y. M. Lee, "Artificial neural network model for forecasting sub-hourly electricity usage in commercial buildings," Energy and Buildings, vol. 111, pp. 184-194, 2016.

[3] M.-Y. Cheng, H.-C. Tsai, and E. Sudjono, "Conceptual cost estimates using evolutionary fuzzy hybrid neural network for 
projects in construction industry," Expert Systems with Applications, vol. 37, no. 6, pp. 4224-4231, 2010.

[4] K. H. Hyari, A. Al-Daraiseh, and M. El-Mashaleh, "Conceptual cost estimation model for engineering services in public construction projects," Journal of Management in Engineering, vol. 32, Article ID 04015021, 2016.

[5] B. Pal, A. Mhashilkar, A. Pandey, B. Nagphase, and V. Chandanshive, "Cost estimation model (CEM) of buildings by ANN (artificial neural networks)-A review," Neural Networks, vol. 5, pp. 1-15, 2018.

[6] J. Liu, X. Li, D. Wu, and J. Dong, "Cost estimation of building individual cooperative housing with crowdfunding model: case of Beijing, China," Journal of Intelligent Manufacturing, vol. 28, no. 3, pp. 749-757, 2017.

[7] H. Piili, A. Happonen, T. Väistö, V. Venkataramanan, J. Partanen, and A. Salminen, "Cost estimation of laser additive manufacturing of stainless steel," Physics Procedia, vol. 78, pp. 388-396, 2015.

[8] O. Tatari and M. Kucukvar, "Cost premium prediction of certified green buildings: a neural network approach," Building and Environment, vol. 46, no. 5, pp. 1081-1086, 2011.

[9] S. C. Lhee, I. Flood, and R. R. Issa, "Development of a two-step neural network-based model to predict construction cost contingency," Journal of Information Technology in Construction (ITcon), vol. 19, pp. 399-411, 2014.

[10] V. Chandanshive and A. R. Kambekar, "Estimation of building construction cost using artificial neural networks," Journal of Soft Computing in Civil Engineering, vol. 3, pp. 91-107, 2019.

[11] J. A. Rodger, "A fuzzy nearest neighbor neural network statistical model for predicting demand for natural gas and energy cost savings in public buildings," Expert Systems with Applications, vol. 41, no. 4, pp. 1813-1829, 2014.

[12] G. Ngowtanasuwan, "Mathematical model for optimization of construction contracting in housing development project," Procedia-Social and Behavioral Sciences, vol. 105, pp. 94-105, 2013.

[13] D.-K. Bui, T. Nguyen, J.-S. Chou, H. Nguyen-Xuan, and T. D. Ngo, "A modified firefly algorithm-artificial neural network expert system for predicting compressive and tensile strength of high-performance concrete," Construction and Building Materials, vol. 180, pp. 320-333, 2018.

[14] E. Asadi, M. G. d. Silva, C. H. Antunes, L. Dias, and L. Glicksman, "Multi-objective optimization for building retrofit: a model using genetic algorithm and artificial neural network and an application," Energy and Buildings, vol. 81, pp. 444-456, 2014.

[15] M. Ceylan, M. H. Arslan, R. Ceylan, M. Y. Kaltakci, and Y. Ozbay, "A new application area of ANN and ANFIS: determination of earthquake load reduction factor of prefabricated industrial buildings," Civil Engineering and Environmental Systems, vol. 27, no. 1, pp. 53-69, 2010.

[16] A. Nasirian, M. Arashpour, B. Abbasi, and A. Akbarnezhad, "Optimal work assignment to multiskilled resources in prefabricated construction," Journal of Construction Engineering and Management, vol. 145, pp. 4019-4034, 2019.

[17] H. Quan, D. Srinivasan, and A. Khosravi, "Particle swarm optimization for construction of neural network-based prediction intervals," Neurocomputing, vol. 127, pp. 172-180, 2014.

[18] H.-L. Yip, H. Fan, and Y.-H. Chiang, "Predicting the maintenance cost of construction equipment: comparison between general regression neural network and Box-Jenkins time series models," Automation in Construction, vol. 38, pp. 3038, 2014.

[19] J. Sobhani, M. Najimi, A. R. Pourkhorshidi, and T. Parhizkar, "Prediction of the compressive strength of no-slump concrete: a comparative study of regression, neural network and ANFIS models," Construction and Building Materials, vol. 24, no. 5, pp. 709-718, 2010.

[20] R. Sonmez, "Range estimation of construction costs using neural networks with bootstrap prediction intervals," Expert Systems with Applications, vol. 38, no. 8, pp. 9913-9917, 2011.

[21] A. O. Elfaki, S. Alatawi, and E. Abushandi, "Using intelligent techniques in construction project cost estimation: 10-year survey," Advances in Civil Engineering, vol. 2014, pp. 10231031, 2014. 